\title{
Substrate specificity and juvenile Favild predominance of coral colonization at the Maldive Islands following the 1998 bleaching event
}

Received: 13 March 2002/ Accepted: 22 November 2002/Published online: 25 March 2003

(C) Springer-Verlag 2003

Keywords Coral reefs · Coral colonization · Coral substrates $\cdot$ Juvenile corals

\section{Introduction}

During the coral bleaching event of 1998 in the Indopacific, there was extensive coral mortality in some areas (Naeem et al. 1998; Edwards et al. 2001; McClanahan et al. 2001; Mumby et al. 2001). For example, observations on North Male Atoll, the Maldives Islands, indicated that up to $90 \%$ of hermatypic corals died following the bleaching event. Prior to the event, $42 \%$ of the reef surface was covered with living hermatypic corals, while only $2 \%$ was covered by living corals after the event (Naeem et al. 1998; Edwards et al. 2001). Two substrates for coral colonization became available in great quantity as a result of coral mortality in 1998: first, numerous coral fragments that resulted from disintegration of dead Acroporidae and other branching corals and, second, the surface of dead, massive corals. Here, we report on colonization of these two substrate types by juvenile corals 3 years after the bleaching event.

S. G. Sprecher $\cdot$ S. Galle $\cdot$ H. Reichert $(\square)$

Institute of Zoology,

Biozentrum/Pharmazentrum,

University of Basel,

Klingelbergstrasse 50, 4056 Basel,

Switzerland

E-mail: heinrich.reichert@unibas.ch

Tel.: + 41-61-2671612

Fax: + 41-61-2671613

\begin{abstract}
Methods
Our study was carried out at 3-6 m depths at five locations on the forereef slope at Rasdhoo Atoll, the Maldive Islands (Fig. 1A) over the period 13-19 May 2001. At each site, several areas of $0.25 \mathrm{~m}^{2}$ (either as $0.50 \times 0.50$ or as $0.25 \times 1-\mathrm{m}$ quadrats) were randomly chosen. The quadrat areas sampled could be divided into two distinct groups based on substrate type. The first type was solid substrate consisting of entire dead coral blocks, which generally had a smooth and hard surface (Fig. 1B). The second type was a fragmented substrate consisting of coral debris and parts of broken branched corals (Fig. 1C). A total of 30 quadrat areas were investigated, with solid and fragmented substrates represented at each of the five sites. The number of new coral colonies and their average diameters were recorded within each quadrat. These colonies had the round or oval form characteristic of juvenile corals, which made it possible to characterize colony size in terms of average diameter.
\end{abstract}

\section{Results and discussion}

A total of 375 coral colonies was found on solid substrates and 16 colonies were found on fragmented substrates. The majority of the 391 colonies belonged to the families Faviidae, Poritidae, Pocilloporidae, or Acroporidae, with only $7 \%$ attributed to other families. Corals down to $15 \mathrm{~m}$ that survived the 1998 mass bleaching at the Maldive Islands were mostly large, massive colonies. None of these was located within our 30 quadrats. All living corals observed within the quadrats were small juvenile colonies.

Colonization was strikingly different between solid and fragmented substrates (Fig. 2A). Colony numbers in the 15 quadrats covering solid substrate ranged from 14 75 , with an average of 25 colonies per quadrat. Almost no colonization was observed on the fragmented substrate. Colony numbers in these 15 quadrats ranged from $0-3$, with an average of 1 colony per quadrat. No colonies were found in 5 of these 15 quadrats. 

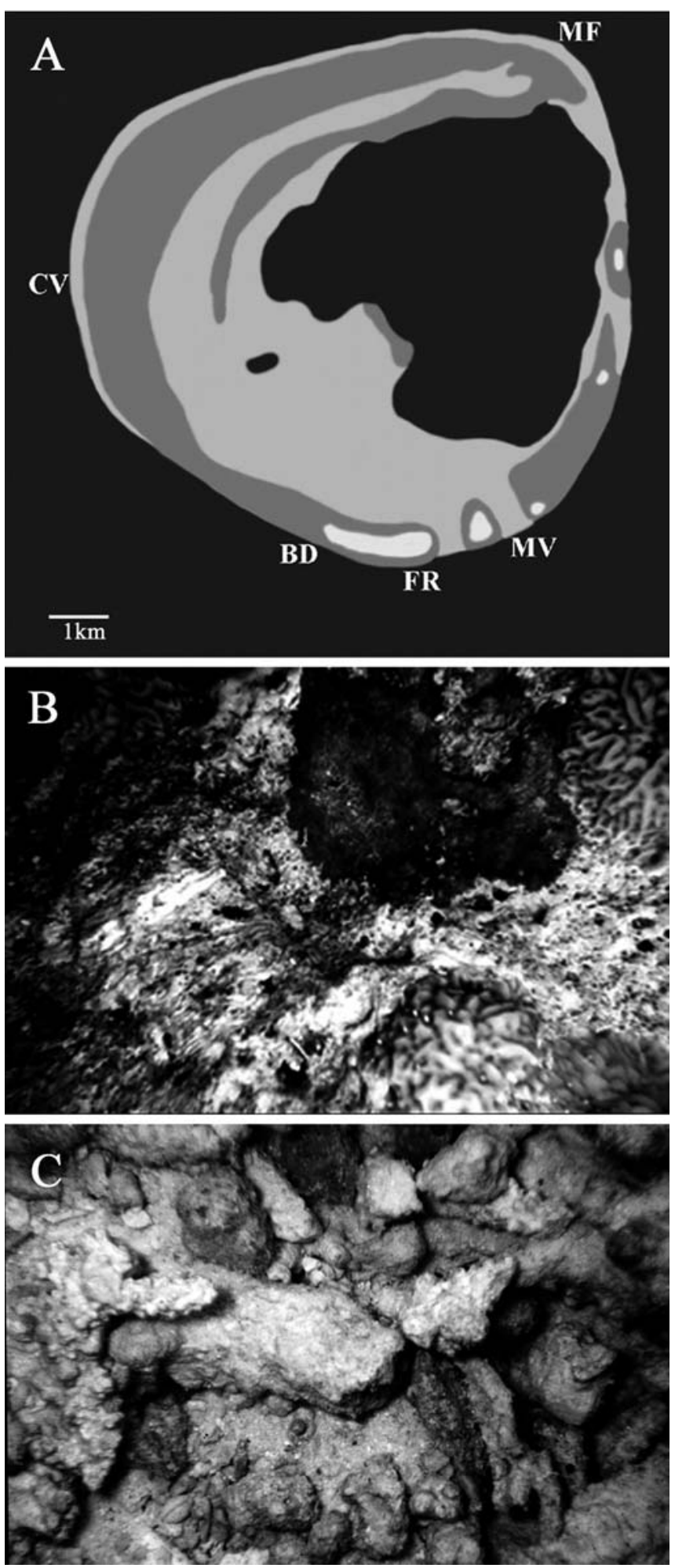

Fig. 1 A Location of the five survey sites around the Rasdhoo Atoll: Caves $(C V)$, Fan Reef $(F R)$, Madivaru $(M V)$, Boduga $(B D)$, and Miyaru Faru $(M F)$. B Example of solid substrate. C Example of fragmented substrate
The average size of colonies was also different between solid and fragmented substrates. The average diameter of colonies on solid substrate was $50 \mathrm{~mm}$ (range 10-200 mm) whereas colonies on fragmented substrates averaged $25 \mathrm{~mm}$ in diameter (range 10 $160 \mathrm{~mm}$ ). Among colonies on solid substrates, members of the Pocilloporidae were the largest, with an average diameter of $102 \mathrm{~mm}$. Members of the Faviidae were the smallest, with an average diameter of $40 \mathrm{~mm}$. Poritidae, Acroporidae and other colonies had intermediate average diameters, ranging from 50-62 mm (Fig. 2B).

Faviids were by far the most common corals settling on solid substrate $(78 \%)$, with members of the Poritidae the next most common (11\%) (Fig. 2C). Across all quadrats covering solid substrate $\left(3.75 \mathrm{~m}^{2}\right)$ there were 294 colonies of Faviidae, 43 colonies of Poritidae, 10 colonies of Pocilloporidae, 3 colonies of Acroporidae, and 25 colonies of other families.

Faviids were also the dominant settlers on fragmented substrates. Of the 15 colonies found on $3.75 \mathrm{~m}^{2}$ of quadrats fragmented substrates, eight were Faviids, two were members of the Poritidae, one was a Pocilloporid, and five belonged to other families.

Qualitative observations indicated that there were no site-specific differences in the number and size of colonies among the five sites at Rasdhoo Atoll, and the contribution of the different coral families to settlement was similar among the five sites. Thus, it appears that recolonization had taken place in a comparable manner at all sites. It is possible that fragmented substrate was avoided by larvae seeking settlement sites or that newly settled larvae and young colonies were quickly killed by disturbance of this substrate by waves and currents. While the reasons for this substrate-dependence are not yet known, the relatively high number of juvenile corals, notably Faviids, on hard substrate demonstrates that considerable colonization had occurred within 3 years. Published information on coral growth rates (see Bak and Engel 1979; Lough and Barnes 2000), together with the size of our colonies, leads us to believe that intensive colonization of the surface of massive corals began shortly after they were killed by the 1998 bleaching event.

Acknowledgements We thank the Tschocke-Stiftung and the Fonds of the Zoological Institute of the University of Basel for support of this project.

\section{References}

Bak RPM, Engel MS (1979) Distribution, abundance and survival of juvenile hermatypic corals (Scleractinia) and the importance of life history strategies in the parent coral community. Mar Biol 54:341-352 
Fig. 2 A Number of coral colonies found within 30 quadrats $\left(0.25 \mathrm{~m}^{2}\right.$ each $)$, half covering solid coral skeleton (left) and half covering coral debris (right). B Average diameter of juvenile coral colonies of various families on solid substrate. C Relative abundance of different families of juvenile corals on solid substrate
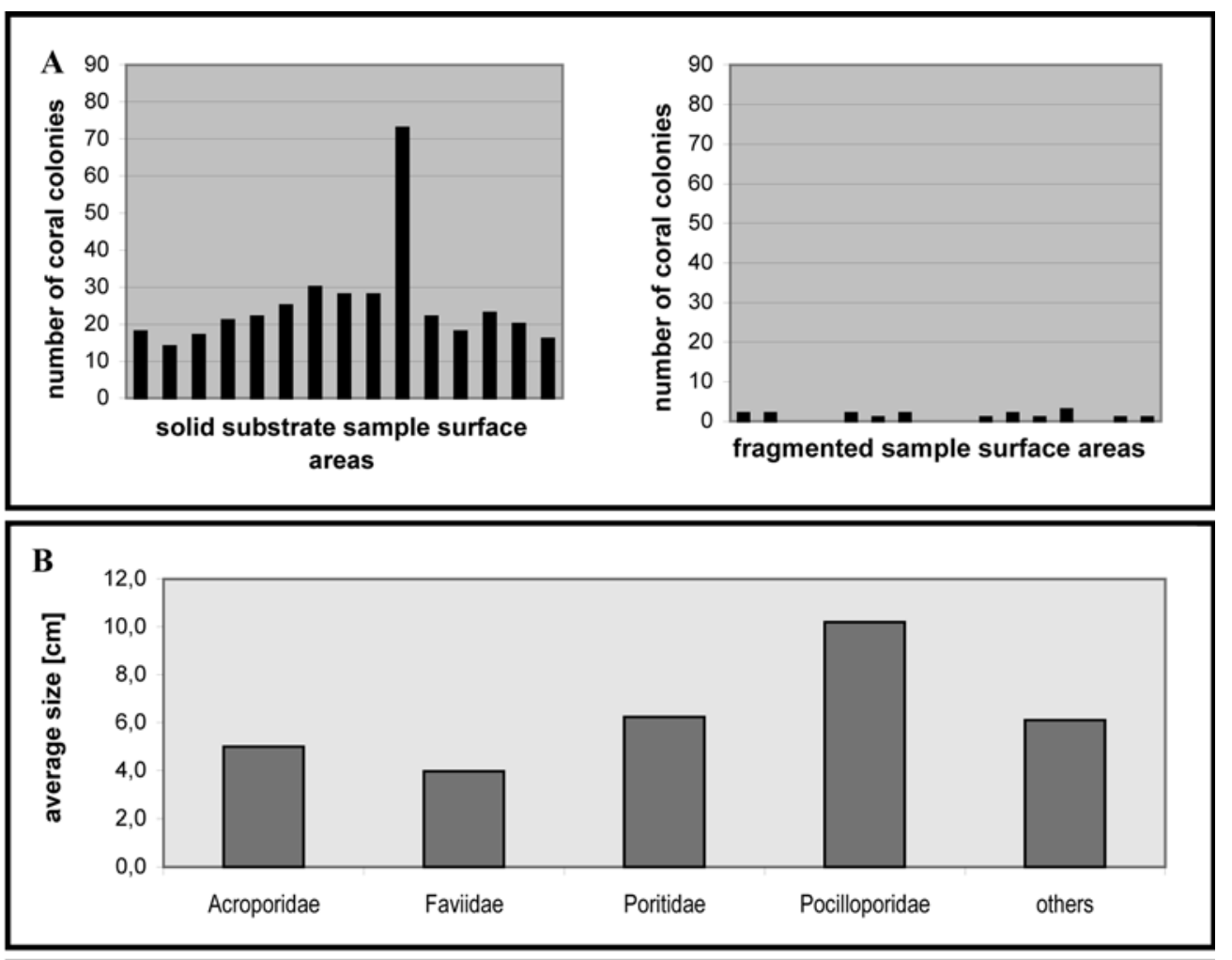

C

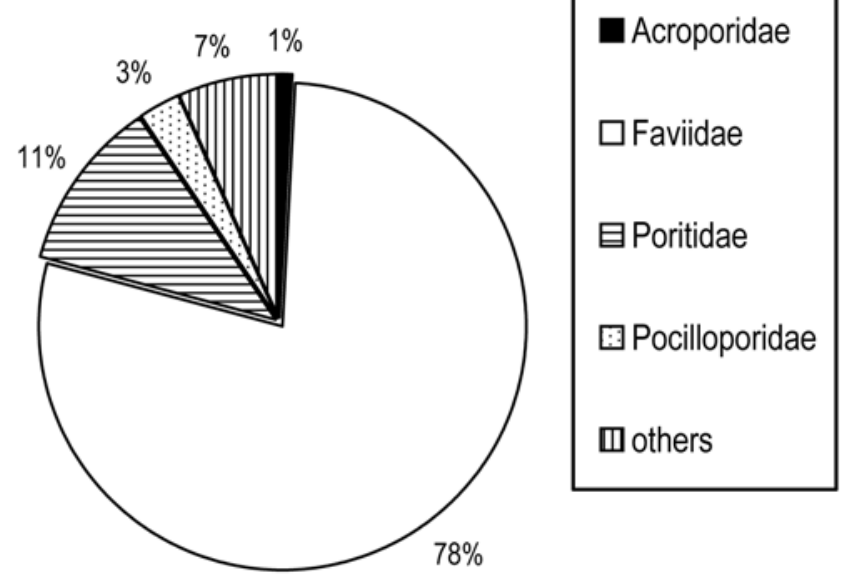

Edwards AJ, Clark S, Zahir H, Rajasuriya A, Naseer A, Rubens J (2001) Coral bleaching and mortality on artificial and natural reefs in Maldives in 1998, sea surface temperature anomalies and initial recovery. Mar Pollut Bull 42(1):7-15

Lough JM, Barnes DJ (2000) Environmental controls on growth of the massive coral Porites. J Exp Mar Biol Ecol 245:225-243

McClanahan TR, McField M, Huitric M, Bergman K, Sala E, Nyström M, Nordemar I, Elfwing T, Muthiga NA (2001) Coral and algal changes after the 1998 coral bleaching: interaction within reef management and herbivores on Kenyan reefs. Coral Reefs 19:367-379

Mumby PJ, Chisholm JRM, Edwards AJ, Clark CD, Roark EB, Andréfouët S, Jaubert J (2001) Unprecedented bleaching-induced mortality in Porites spp. at Rangiroa Atoll, French Polynesia. Mar Biol 139:183-189

Naeem I, Rasheed A, Zuhair M, Riyaz M (1998) Coral bleaching in the Maldives. Survey carried out in the north and south Male atolls. Marine Research Section and Environment Research Unit 